\title{
Contrasting stakeholder and scientist conceptual models of food- energy-water systems: a case study in Magic Valley, Southern Idaho
}

\author{
Grace B. Villamor ${ }^{1,2,3^{*}}$, David L. Griffith², Andrew Kliskey² and Lilian Alessa² \\ ${ }^{1}$ Scion (New Zealand Forest Research Institute, Ltd.), New Zealand \\ ${ }^{2}$ Center for Resilient Communities, University of Idaho, USA \\ ${ }^{3}$ University of Bonn, Germany
}

\begin{abstract}
One of the factors for the success of simulation studies is close collaboration with stakeholders in developing a conceptual model. Conceptual models are a useful tool for communicating and understanding how real systems work. However, models or frameworks that are not aligned with the perceptions and understanding of local stakeholders can induce uncertainties in the model outcomes. We focus on two sources of epistemic uncertainty in building conceptual models of food-energy-water systems (FEWS): (1) context and framing; and (2) model structure uncertainty. To address these uncertainties, we co-produced a FEWS conceptual model with key stakeholders using the Actor-Resources-Dynamics-Interaction (ARDI) method. The method was adopted to specifically integrate public (and local) knowledge of stakeholders in the Magic Valley region of Southern Idaho into a FEWS model. We first used the ARDI method with scientists and modellers (from various disciplines) conducting research in the system, and then repeated the process with local stakeholders. We compared results from the two cohorts and refined the conceptual model to align with local stakeholders' understanding of the FEWS. This co-development of a conceptual model with local stakeholders ensured the incorporation of different perspectives and types of knowledge of key actors within the socio-ecological systems models.
\end{abstract}

\section{Keywords}

ARDI method; co-conceptual model development; food-energy-water nexus; stakeholder involvement; epistemic uncertainties

\section{Introduction}

Food, energy, and water systems (FEWS) are interrelated with one another. There is a growing number of studies on understanding the complex relationships of food, energy, and water in different landscapes (e.g., water-foodenergy nexus; see Endo et al., 2017). Because of the complexity of FEWS, the assessment of trade-offs and synergies in the system of systems are best assessed using integrated modelling approaches (Bazilian et al., 2011; Zhang \& Vesselinov, 2017). Several integrated modelling frameworks have been developed in recent years with the intention of simulating the complex dynamics of target systems such as: the Climate, Land, Energy and Water model by Bazilian et al. (2011); the WEF nexus Tool 2.0 by Daher and Mohtar (2015); and the Water Energy and Food security nexus Optimization (WEFO) model by Zhang and Vesselinov (2017). As with other integrated environmental modelling approaches, FEWS models face significant challenges and issues.

\footnotetext{
Correspondence:

Contact G. Villamor at gracev@uni-bonn.de

Cite this article as:

Villamor, G.B., Griffith, D.L., Kliskey, A. \& Alessa, L.

Contrasting stakeholder and scientist conceptual models of food-energy-water systems: a case study in Magic Valley, Southern Idaho

Socio-Environmental Systems Modelling, vol. 2, 16312, 2020, doi:10.18174/sesmo.2020a16312
}

This work is licensed under a Creative Commons Attribution-NonCommercial 4.0 International License. 
One of these is the issue of uncertainty. There are many definitions of uncertainty. For example, Walker et al. (2003) define it as: "the degree of lack of knowledge about a system or processes or degree of inability to exactly describe its state or behaviour;" Klauer and Brown (2004) and Refsgaard et al. (2007) as "the degree of confidence a person has about the specific outcome of an event or action;" and Brugnach et al. (2007) as "the situation in which a decision maker does not have a unique and complete understanding of the system to be managed." Indeed, all of these definitions are based on the concept that uncertainty derives from people's lack of knowledge about natural systems (Warminck et al. 2010). Furthermore, this lack of knowledge about the systems is associated with the concept of epistemic uncertainty, which refers to scientific uncertainty about modeled processes due to limited data and knowledge. Here, we focus on two sources of epistemic uncertainty in FEWS conceptual model formulation, which are also part of the challenges of modelling at the nexus of multiple complex systems as identified by Garcia and You (2016):

1. Context uncertainty, which refers to the conditions and circumstances that lead to the choice of boundaries of a system, and the framing of the issues and formulation of problems to be addressed within those boundaries. This includes uncertainties about the economic, environmental, political, social, and technological situation that forms the context for problems being examined; and

2. Model (structure) uncertainty, which is associated with the conceptual model (which includes variables and their relationships) and how it represents a real system (including its specification, behaviour, fundamental assumptions, and possible future evolution). It arises from a lack of sufficient understanding of the system.

Furthermore, in a complex system such as a FEWS there exist many organizations, institutions, and stakeholders, and each of them has their own view and knowledge of how the system works, and they often have objectives in competition with those of other stakeholders (Ascough et al., 2008; Brugnach et al., 2008; Villamor et al., 2014). The challenge is to design a modelling tool to enable a productive and meaningful integration of scientific and stakeholder (i.e., local people) knowledge of the social-ecological systems of interests and to address the abovementioned uncertainties. In this context, "knowledge" refers to how systems are modelled in the world according to different modes of acquisition of facts, information, and skills rather than trying to replicate how people think (Clancey, 1993). Thus, stakeholder knowledge of a system differs not only from the knowledge of researchers, but also tends to differ from that of other stakeholders. In effect, stakeholders often have preferred management strategies or policies which can have profound ecological and environmental impacts on FEWS. Scientists also have differences in knowledge deriving from various fields and schools of thought, leading to individuals favouring methods or tools they are familiar with.

Traditionally, uncertainty assessment or analysis is carried out only at the end of a modelling study when models have been calibrated and validated (Refsgaard et al., 2007). However, to better integrate model results into a broader resource management process, it is important to conduct uncertainty assessment at the beginning of a modelling process (Refsgaard et al., 2005). Different methodologies and tools can be applied for uncertainty assessment, and one such method is to include stakeholder input in the modelling process (Refsgaard et al., 2007). The efforts reported here are the result of co-development of a conceptual model of the FEWS in the Magic Valley region of Southern Idaho. This paper builds on the premise that involving stakeholders in the conceptual modelling process can help to characterize elements of uncertainty (i.e., epistemic uncertainty).

\subsection{Overview}

Conceptual modelling is an important step in model process building and simulation (Argent et al., 2016; Gupta et al., 2012, Robinson 2008). It is a process of abstracting a model from a real or proposed system (Robinson 2008), understanding the problematic situation, and deciding what is to be represented and how it is to be represented in the simulation model (Tako et al., 2010). All of these are central to epistemic uncertainty. However, models are often developed by a lone modeller acting as an internal or external consultant. This is also different to the nature of simulation of complex interactions of systems (e.g., socio-ecological systems, FEWS) where they are usually developed by a team of researchers.

There are several advantages of using conceptual models and involving stakeholders in the process. Among these are that it can:

1. Provide a roadmap from the problem situation and objectives to model design and software implementation (Pace, 2003); 
2. Aid the process of model design (affecting the model structure uncertainty) (Robinson, 2008). Together with stakeholders, it enables the modeller to carefully design a model, elucidate key components, and identify important relationships among those components;

3. Form a basis for model documentation and development of a computer model; and

4. Serve as a platform for integrating stakeholder and researcher knowledge as a way to reduce epistemic uncertainty.

The first two advantages are related to uncertainty, and the first is particularly related to context uncertainty. According to Pahl-Wostl et al. (2007), during the initial stages of dealing with a problem situation the processes involved in framing and reframing a problem domain strongly influence the direction of the overall managing (or modelling) process. The framing of a resource management situation defines what is at stake and who should be included and in what role (Brugnach et al., 2008). The second advantage is associated with the model structure. This includes variables and the relationships between model components, which are chosen (by stakeholders and scientists) to describe a system and its boundaries.

This study builds on the premise that the more knowledge is integrated in the initial modelling stages, the more it will reduce epistemic uncertainty (Brugnach et al., 2008; Refsgaard et al., 2007). However, the identification of uncertainties rarely takes place in a structured and consistent manner (Warmink et al. 2010). This paper does not focus on quantitative identification of uncertainties, but rather on identifying those uncertainties in the crucial first stages of the modelling process. The primary aim, then, is to describe the key structures of a specific system according to two knowledge systems: namely, scientific and public/local knowledge (Villamor et al., 2014). By doing so, we can compare whether the public/local knowledge system is coherent with scientists' knowledge of the same system, and this allows us to address epistemic uncertainty by adjusting the way the scientists view the system (before developing quantitative models of a food, energy and water [FEW] system).

\subsection{ARDI for co-conceptual model to agent-based FEWS nexus model}

In understanding the nexus of food, energy, and water systems, social-ecological systems (SES) science approaches are relevant because of society's reliance on essential services such as water, energy, and food resources (Berkes \& Folke, 1998). The natural landscapes and components of these systems that provide ecosystem services are also affected by human development, decision making, and resource exploitation. In recent years, agent-based modelling frameworks have become a recognized model for understanding SES dynamics because of its strong incorporation of human decision making and behaviour (An, 2012; Villamor and van Noordwijk, 2016). Agent-based modelling is a computational method for simulating the actions and interactions of autonomous decision-making entities in a system with the aim of assessing their effects on the whole system (Dawson et al., 2011). Despite its wide application, the modelling results are not immune to a high degree of uncertainty (e.g. representation of the model outputs to reality). According to Filatova et al. (2013), learning about SES functioning and identifying critical knowledge gaps in representing SES can address the uncertainties and errors in specifying specific components in the design and parameterization of decision rules of agents. In representing complex interactions such as a FEWS, a modeller or scientist may miss or ignore key interactions that are crucial to real people in a certain landscape. One way to address this type of uncertainty is through involvement of key stakeholders in the modelling processes (d'Aquino \& Bah, 2013; Refsgaard et al., 2007). Modelling with stakeholders has a variety of descriptive names: companion modelling, group model building, mediated modelling, shared vision planning, and participatory simulation have been widely implemented in natural resources management (Barreteau et al., 2012), which emphasizes the importance of involving stakeholders in the modelling process (Voinov et al., 2016; Voinov \& Bousquet, 2010). For example, a participatory agent-based model $(A B M)$ incorporates on-site decision making from real people, facilitating information sharing, collective learning, and exchange of perceptions on a given concrete issue among researchers and stakeholders (Naivinit et al. 2010).

A useful method for companion modelling is the Actor-Resources-Dynamics-Interactions (ARDI) framework (Étienne et al., 2011; Étienne, 2013). It is designed to provide a framework for stakeholders to think through and describe the dynamic state of a given social-ecological system. It helps characterize the relationship between the process of planning and decision making and the resulting environmental, economic, and social impacts of concern to stakeholders (Basco-Carrera et al., 2017). Its main output is a collective conceptual model of the involved stakeholders, which is useful in constructing role-playing games and computer-based simulation models such as agent-based models (Dumrongrojwatthana et al., 2011; Étienne, 2013; Gourmelon et al., 2013; 
Villamor et al., 2014). With this method, the development of an ABM is easier because actors can be translated to agents, the dynamics and processes to sub-models, and interactions can be used to describe rule-based decisions between bio-physical and social systems (Villamor et al., 2012). Using ARDI as a conceptual model provides a sense-making device to perceive and communicate knowledge about the SES interactions (Lynam et al., 2012). Furthermore, comparing and adjusting the conceptualizations between different knowledge systems is related with the treatment of uncertainties in participatory modelling particularly on the input side as proposed by Voinov et al. (2016).

In the following sections, we first introduce the Magic Valley as the case study. Then, we briefly describe the different components of the ARDI framework and the method of fulfilling those components through data collection and analysis. The ARDI results are presented according to each group's knowledge and the re-adjusted understanding of the system. Afterwards, the different identified components are synthesized and we then address how uncertainties are represented in the ARDI process. A section on lessons learned is also presented before the overall conclusions of the paper.

\section{Methods}

\subsection{Magic Valley: study area}

The Magic Valley occupies 33,457 km² of the Upper Snake River Basin in south-central Idaho (Figure 1). It consists of eight counties, and Twin Falls is the region's largest city with an estimated population of 49,202 (U.S. Census Bureau, 2017). Agricultural production and dairy operations are the major economic engine of the region as well as for the economy of the State of Idaho. In 2012, the region had agricultural sales amounting to $\$ 3.5$ billion USD of which $\$ 682$ million USD was net income (USDA, 2012).

There are also food processors and aquaculture operations in the region. Glanbia and Chobani are the two largest food processing companies for dairy products in the region and are major producers of commodity cheese and yoghurt, respectively, while the Amalgamated Sugar Company is the main buyer for sugar beets and a leading producer of processed sugar in the United States. Furthermore, the Magic Valley is considered the number one producer of farmed trout in the United States (NASS, 2017). All of this agricultural and food production depends on water from surface or ground water, and the entire region lies within the confines of the Eastern Snake Plain Aquifer (ESPA). At the same time, residents in the municipalities compete with farmers and producers for water while the food and dairy industries and municipalities discharge wastewater which makes its way into surface waters or infiltrates

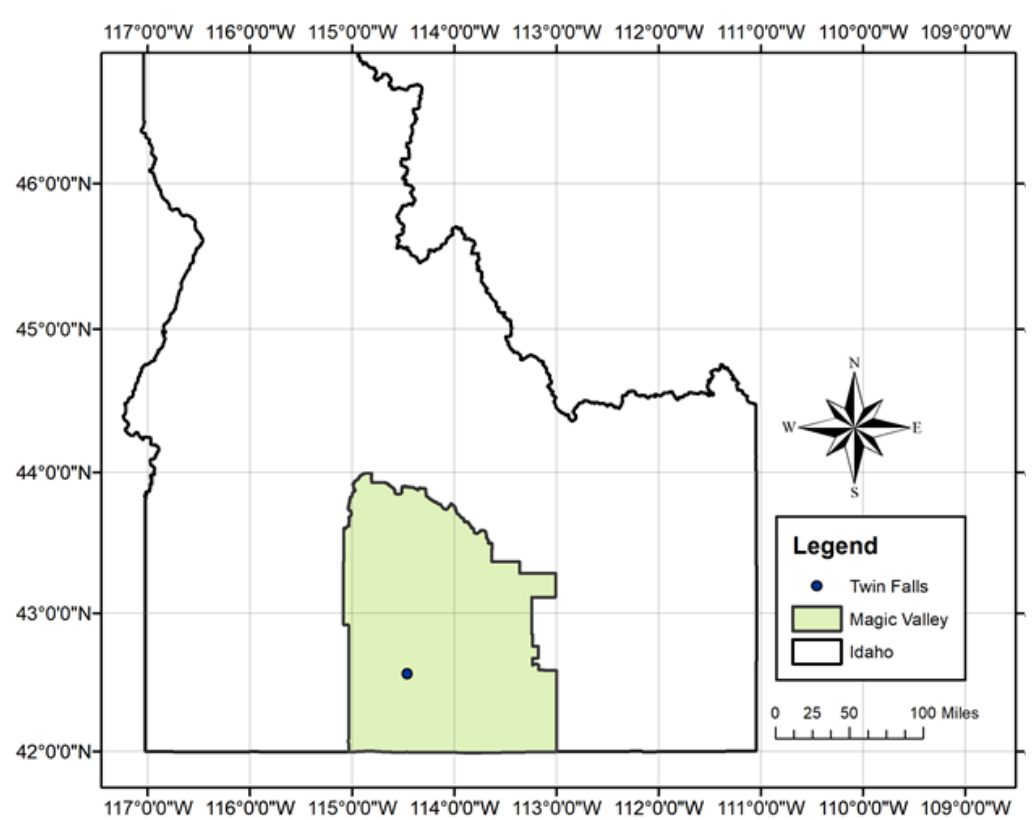

Figure 1: Map of Magic Valley, South-central Idaho, USA into the groundwater. 


\subsection{ARDI framework}

ARDI is the conceptual framework of this study, which is described in detail by Etienne et al. (2011). ARDI frames the elicitation of individual knowledge that then leads to the emergence of collective learning. Sharing of representations of each stage leads to progressive emergence of a collective conceptual model. There are four different stages to this approach, which are briefly described below.

i. Identifying key actors $(\mathrm{A})$ : by listing stakeholders and their corresponding management entities and linkages between them. The participants identify these stakeholders as either "direct" (whose practices have direct impacts on key resources) or "indirect" (whose actions have influence on the direct stakeholders to change their practices).

ii. Identifying key resources (R): by listing the relevant resources (exclusively products) of the study area according to the key stakeholders previously identified. For this study, FEW resources were targeted.

iii. Identifying key dynamics (D): by listing the main processes that drive resource dynamics in the study area. The processes may deal with ecological (e.g., water flow), economic (e.g., changing agricultural input prices), or social dynamics (e.g., collectivism or cultural identity).

iv. Eliciting interactions (I): by collectively constructing an interaction diagram describing linkages among the identified stakeholders and resources. The participants also suggest a verb that characterizes the type of action that generates each linkage.

Once the listings of key actors, resources, and dynamics were prepared, the participants ranked those according to their importance.

\subsection{Data collection and analysis}

A total of four workshops and focus group discussions (FGD) were conducted between January and July 2018. The first (scientific) group was composed of eight researchers and scientists from various disciplines including geography, ecology, environmental policy, environmental science, hydrology, and economics. This group is building FEWS models of the Magic Valley as part of an NSF-funded research program to develop integrated modelling for FEWS. The second (local stakeholders) group was composed of local dairymen (2), a crop farmer (1), a food processing representative (1), a livestock extension agent (1), an NGO representative (1), and a waterrights lawyer (1). The food processing representative is also a dairy and crop farmer. The participants in the second group were identified by a stakeholder advisory group (SAG) established in the beginning of 2017 to guide and inform integrated modelling efforts. SAG members were recruited from communities in the study area and represent a wide range of sector expertise, ages, educational background, and genders. The SAG includes farmers (both crop and dairy), food processors, canal company personnel, an extension agent, municipal water managers, and a water rights lawyer. Prior to the conceptual modelling workshops, two SAG meetings were conducted in May and November 2017 to define research problems relating to the FEWS in the Magic Valley. Building on the SAG meetings, the design for implementing the ARDI method was modified. The key resources were identified during the SAG meetings; namely, the water (i.e., surface and ground) and wastes/by-products from agricultural production and dairy operations. Thus, the modelling workshops revolved around identifying key elements in the structure of the FEWS: (1) actors who could or should play a role in managing or deciding the use of water (surface and ground) and wastes; (2) dynamics and processes that drive changes in the Magic Valley; and (3) interactions that link the actors and resources and affect how actors perceive the sub-systems to function.

For identifying the most important actors and dynamics affecting system change, the participants were asked to rank the top three actors (i.e., 1 to 3 and 1 as the highest rank) and top five dynamics in the system. The results were analysed by comparing these key structures according to knowledge groups and assessing whether they share the same conception of the FEWS in the Magic Valley. Two FGDs were conducted with the Idaho Dairymen Association (IDA) and a sugar beet consultant with the aim of verifying or extending the results of the three workshops. The ranking procedure allows modellers and scientists to identify the important processes and actors that should be in the model and the data to be collected for the model development. At the end of the exercises, we compared the results by identifying the differences in terms of key actors, the most important dynamics and processes as well as the different actions between actors and key resources. 


\section{Results and discussion}

\subsection{Key actors}

Figure 2 depicts the key actors in the Magic Valley who have direct roles in deciding the use of water and agricultural wastes. Differences in perspectives are evident between the two knowledge groups:

I. Local stakeholders (water): end users of water were classified according to water sources, which were the top two ranked direct actors. The end users consisted of property owners with ground water pumps such as dairies and surface water users such as crop farmers, food processors, and municipalities. Particular attention was given to those local stakeholders that are using ground water due to the problem of aquifer recharge. The U.S. Bureau of Reclamation was ranked as the third most important actor, due to control of surface water storage and release through managing impoundments on the Snake River and tributaries.

II. Scientists/modellers (water): Idaho Power Co. was ranked as the most important, followed by aquaculture operations and farmers. They classified actors according to use, e.g., grouped together dairy and crop production as one key actor - "farmers" (both surface and ground water for food), whereas aquaculture (surface water for food) and Idaho Power Co. (surface water used for generating electricity) were considered distinct by how they were using water (rather than by how much water they were using).

III. Difference/adjustment of understanding (water): As clarified by the local stakeholders, the water source is divided (surface vs. ground) but use is mixed. For example, a dairy operation in a county on the south side of the Snake River canyon might solely use surface water, whereas food processors/industries north of the river are using both surface and ground water. The local stakeholders underscored the important role of the Bureau of Reclamation, which manages the reservoirs to store water and release water through contracts with canal and power companies (i.e., Idaho Power) for irrigation use, electricity production, and flood control. Although the irrigators and canal companies monitor the amount of water in reservoirs, the Bureau has the authority to regulate the water flows and implement policy. In this way of conceptualizing the FEWS, power companies, canal companies, the Idaho water board, the state legislature, and the public were identified as indirect actors.

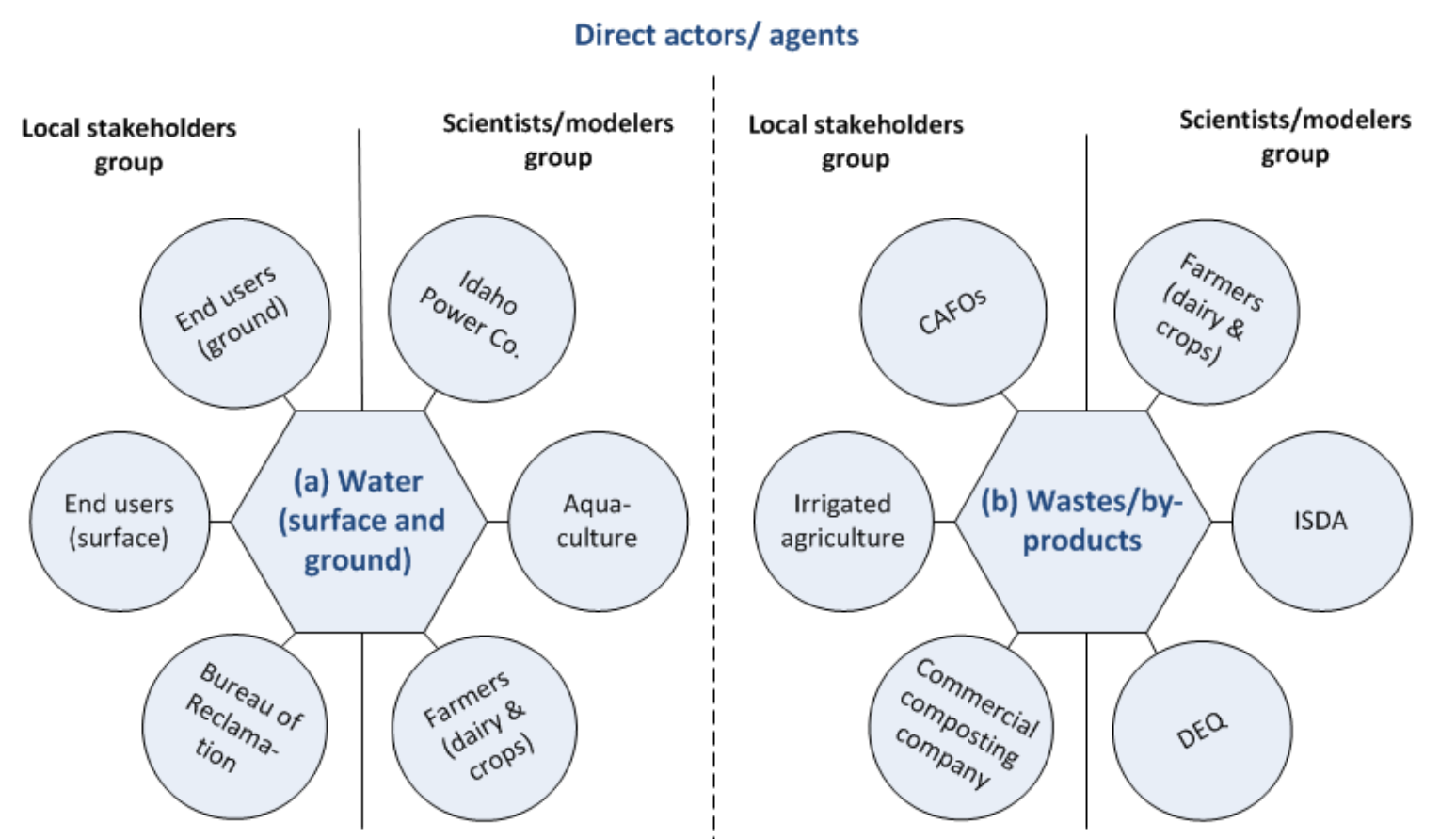

CAFOs = Concentrated Animal Feeding Operations; ISDA = Idaho State Department of Agriculture; DEQ = Idaho Department of Environmental Quality

Figure 2: Actors who play major roles in managing and deciding the use of water (a) and wastes from agriculture and dairy production (b). 
Regarding waste, the following are the main differences identified:

I. Local stakeholders (wastes): classified separately the concentrated animal feeding operations (CAFOs) from irrigated agriculture as two different actors, which are the top two ranked direct actors. The commercial waste/composting companies (e.g., Southern Idaho Solid Waste Co., Magic Valley Compost, etc.) ranked the third most important actor for waste/by-products management. In this context, "wastes" includes dairy manure, nutrient run-off, and other products of the system which either accumulate or contaminate water and land as they leave the system.

II. Scientists/modelers (wastes): as when discussing water resources, they aggregated dairy and crop production as one actor and perceived it as the most important in the system. The Idaho Departments of Agriculture (ISDA) and Environmental Quality (DEQ) were ranked as the second and third actors.

III. Difference/adjustment of understanding (waste/by-products): The local stakeholders underscored the differences between CAFOs (which primarily means dairy operations in the Magic Valley) and irrigation crop agriculture. Aside from the differences in volume and types of waste generated, the two actors are different because they are regulated differently by state agencies (i.e., CAFOs are highly regulated when it comes to nutrient management, while irrigated crop agriculture is not as regulated). Depending on stakeholder perception, the ranking of the top two actors could be changed: for example, the dairy farmers perceived crop farmers as the top contributor of agricultural wastes (in the form of nutrient accumulation and leaching from over-fertilization) because they considered themselves as highly regulated in terms of waste management; whereas crop farmers perceived CAFOs as top waste producers because of the odor and the volume of manure generated. The ISDA and DEQ, which were seen by the scientists/modelers group as important direct actors, are viewed by the local stakeholders as indirect actors. In addition, the local stakeholders underscored the role of commercial waste companies as direct actors due to their role in disposing and recycling animal carcasses, biosolids, and crop residue, which the scientists/modelers group were not aware of.

\subsection{Dynamics and processes}

The following are the main dynamics and processes creating change in the Magic Valley in relation to water and wastes/by-products according to local stakeholders and scientists/modellers groups. Figure 2 and 3 illustrate the main dynamics or processes.

I. Local stakeholders (water): Snowpack, precipitation, and recharge were identified as important processes in the "biophysical" category, which was ranked as the most important dynamics/processes (Table 1). The "technological" category was ranked second and included methods of water storage, transportation, and monitoring/management. The cost of electricity was an indirect but very powerful driver of local processes (by affecting the cost of pumping ground water).

II. Scientists/modellers (water): Aquifer level (biophysical) and water rights (policy) were tied for most important, followed by type and price of crops or commodities. Hydrological cycle and population growth ranked as fourth and fifth most important, respectively.

III. Difference/ adjustment of understanding (water): It is expected that scientists/modellers highlighted the biophysical processes, which were also noted by local stakeholders. However, local stakeholders emphasized that snowpack and precipitation determine the water availability for the whole Magic Valley, whereas scientists/ modellers emphasized aquifer level. Both groups identify population growth as important social dynamics; whereas, the cost of electricity was viewed by local stakeholders as one of the most important drivers of change. For local stakeholders, the cost of regulation (implementation of water rights) is seen as another important dynamic rather than just regulation in its own right.

Table 1: Ranking of dynamics and processes affecting the water in Magic Valley.

\begin{tabular}{clcl}
\hline & Local stakeholder knowledge & & \multicolumn{1}{c}{ Scientists/modellers knowledge } \\
\hline Rank & \multicolumn{1}{c}{ Dynamics/processes } & Rank & \multicolumn{1}{c}{ Dynamics/processes } \\
\hline 1 & Snowpack/ precipitation (recharge) & 1 & Aquifer level \\
2 & Water storage/infrastructure & 1 & Water/property rights (regulation) \\
3 & Prices of commodities & 2 & Type/price of crops, land and dairy \\
4 & Population growth (perception/pressure) & 3 & Hydrological cycle \\
5 & Cost of electricity (i.e., irrigation) & 3 & Population growth \\
\hline
\end{tabular}




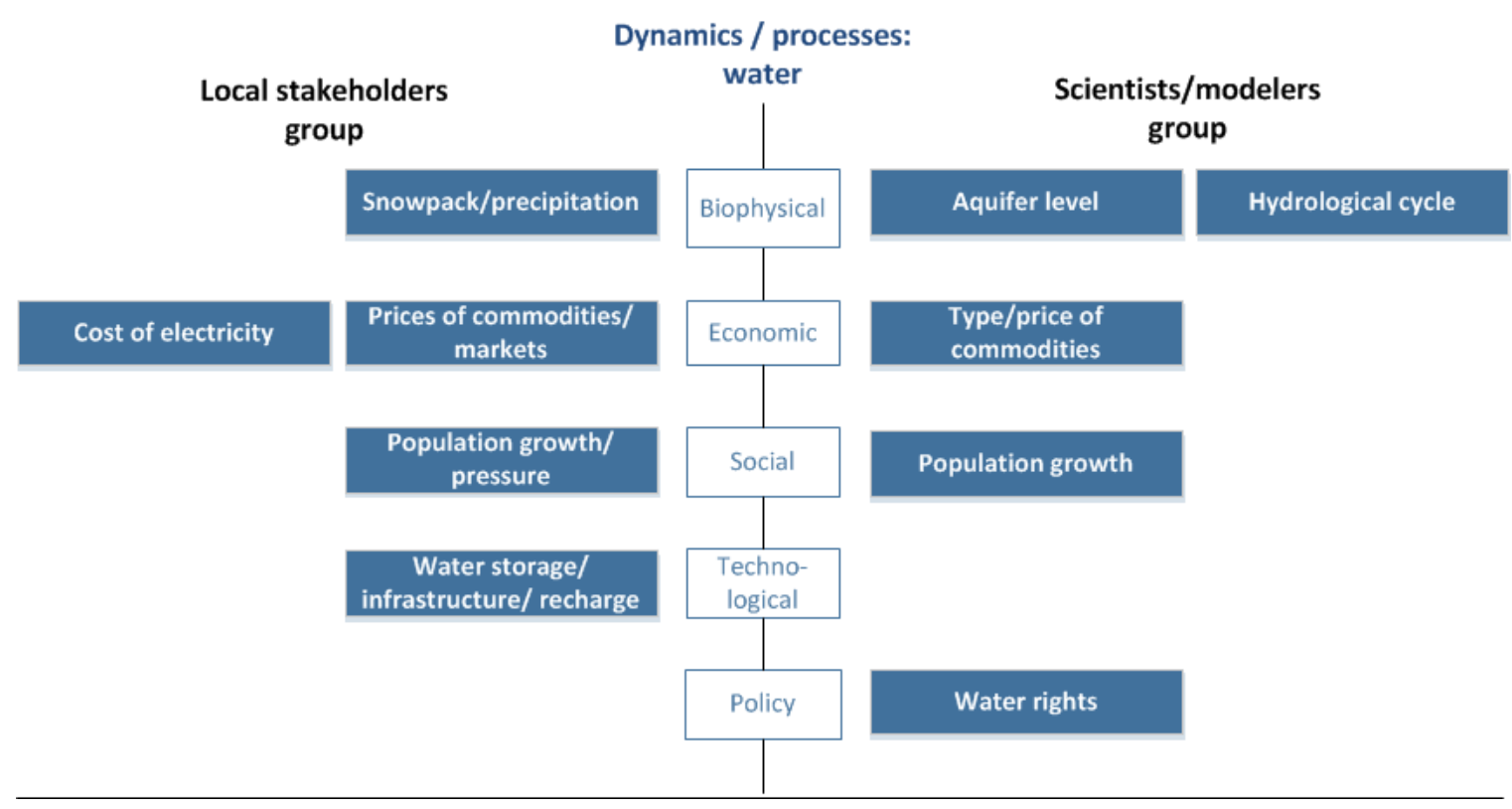

Figure 3: Key dynamics and processes creating changes in relation to water resources in Magic Valley.

For agricultural wastes and by-products, the following are the main dynamics and processes identified:

I. Local stakeholders (waste/by-products): The cost of treatment and disposal and cost of transportation ranked as the first and second most important dynamics affecting the system. They underscored that the price of oil and petroleum dictates the amount and source of fertilizer and compost use. In 2007 and 2008, regional dairy farmers were able to sell their manure as fertilizer due to high oil prices (which increased the price of shipping for inorganic fertilizer from outside the region), and they see this as a dynamic which could happen again. The third most important dynamic in terms of waste management, specifically for the dairy industry, is a serious regional labour shortage; recent changes in national immigration policy have made it very difficult for the dairy industry to hire and maintain on-farm help in an area with extremely low unemployment (Table 2).

II. Scientists/modellers (waste/by-products): The five dynamics depicted in Figure 4 were determined as having the same level of importance. These included: livestock type; cost of transportation; land-use (crop vs. dairy); mandated management plans (by regulation); and farmers' social networks.

III. Difference/adjustment of understanding (waste/by-products): The local stakeholders identified economic dynamics as the major processes affecting the study area. Eliciting the local stakeholders' perception on the costs of transportation and electricity helped the scientists/modellers to understand why bio-digester plants are not being utilized in the region as a solution to convert manure to bioenergy. The main reasons are: 1) the landfill fees are low; 2) land is available to dump the wastes (e.g., manure); and 3) electricity from hydropower is very cheap. The scientists/modellers group failed to acknowledge the importance of labour supply in the waste/by-product management. For the dairy industry in the Magic Valley there is a $10 \%$ labour shortage, whereas for the whole agricultural sector there has been a $50 \%$ labour shortage in Idaho for more than a decade according to local stakeholders. The scientists/modellers group paid more attention to population growth and cultural inertia; the stakeholder acknowledged these as important in general, but insisted they had no immediate impact on waste management.

Table 2: Ranking of dynamics and processes affecting the wastes in Magic Valley.

\begin{tabular}{clcl}
\hline & Local stakeholder knowledge & & \multicolumn{1}{c}{ Scientists/modellers knowledge } \\
\hline Rank & \multicolumn{1}{c}{ Dynamics/ processes } & Rank & \multicolumn{1}{c}{ Dynamics/ processes } \\
\hline 1 & Cost of treatment/disposal/ amendment & 1 & Type of livestock \\
2 & Cost of transportation (by-products) & 1 & Farmer networks/ cultural enertia \\
3 & Regulations/laws & 1 & Cost of transportation (by-products) \\
4 & Workforce development/ labour supply & 1 & Land use (crop vs. dairy) \\
5 & Information/ education & 1 & Mandated management plan \\
\hline
\end{tabular}




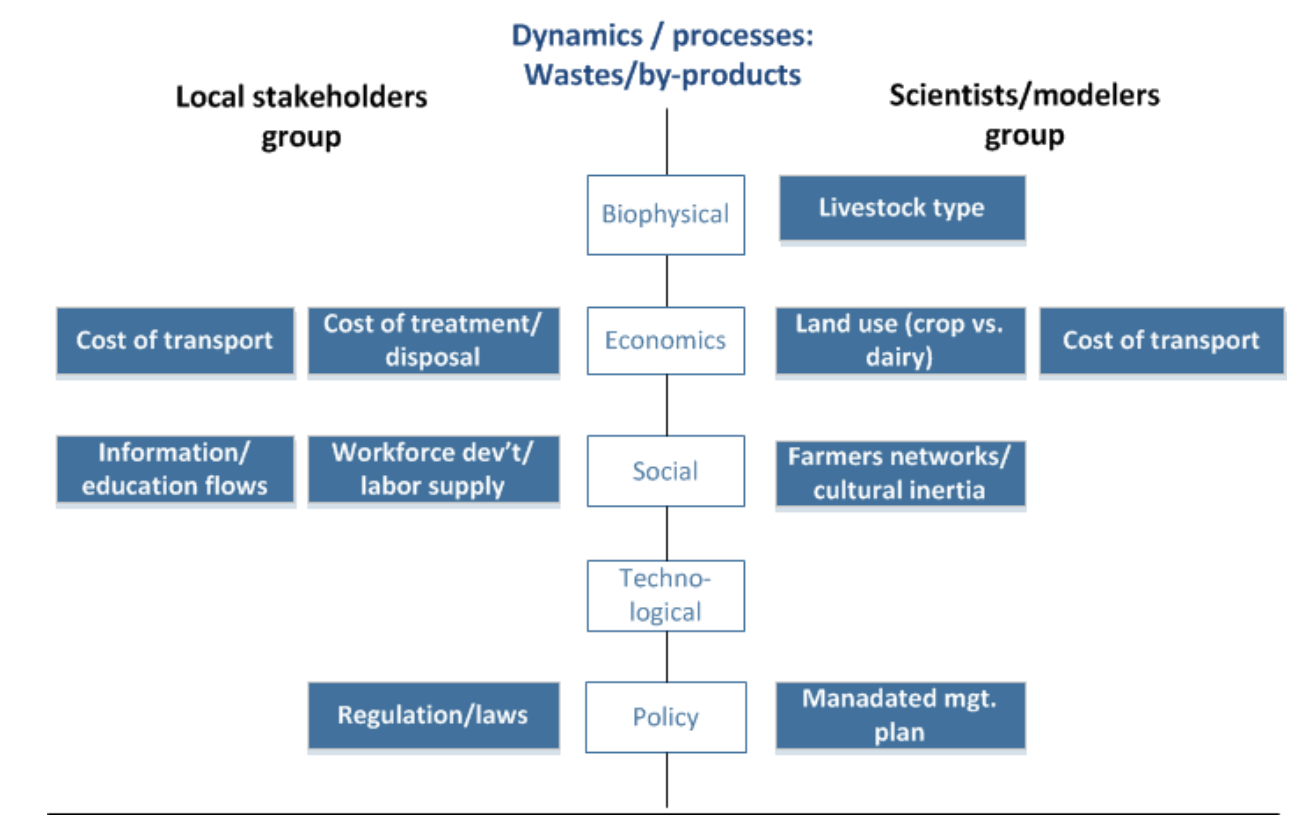

Figure 4: Key dynamics and processes creating changes in relation to wastes/by-products in Magic Valley

\subsection{FEWS conceptual model}

Figure 5 presents the conceptual model developed by scientists and modelers before the stakeholders' involvement, whereas Figure 6 presents a modified conceptual model after the stakeholders' involvement.

In Figure 5, the scientists and modelers were confident they were able to identify various links and feedbacks based on integrating their knowledge from different domains (e.g., ecological, hydrological, and socio-economic aspects of water and waste/by-products). During the process of synthesizing the links between key actors, dynamics and interactions, water resources were further broken down into three sub-levels (surface, subsurface, and groundwater). For each sub-level, indirect actors were included as actors influencing the decisions of the key actors (illustrated as white boxes). This includes canal companies, Idaho Department of Water Resources (IDWR), and the state water commission. A direct actor (i.e., water board) was linked for sub-surface water. For wastes/by-products, the food processing industry and EPA were added as indirect actors through generating demand or regulating nutrient flows.

Developing process and ABMs from this conceptualization (Figure 5) and generating outputs may provide understanding of the FEW nexus, but the validity of model outputs is uncertain due to a lack of local knowledge by the scientific/modeling team. For one thing, it includes as direct actors some that are viewed by the local stakeholders as only indirectly influencing the system, and the conceptualization misses out on some of the most important interactions (i.e., an over-simplification). Furthermore, the drivers of change in the FEW system dynamics are primarily bio-physical, and because of this we can expect that potential solutions or strategies are technical or technological and may not be well-suited to stakeholder needs. 


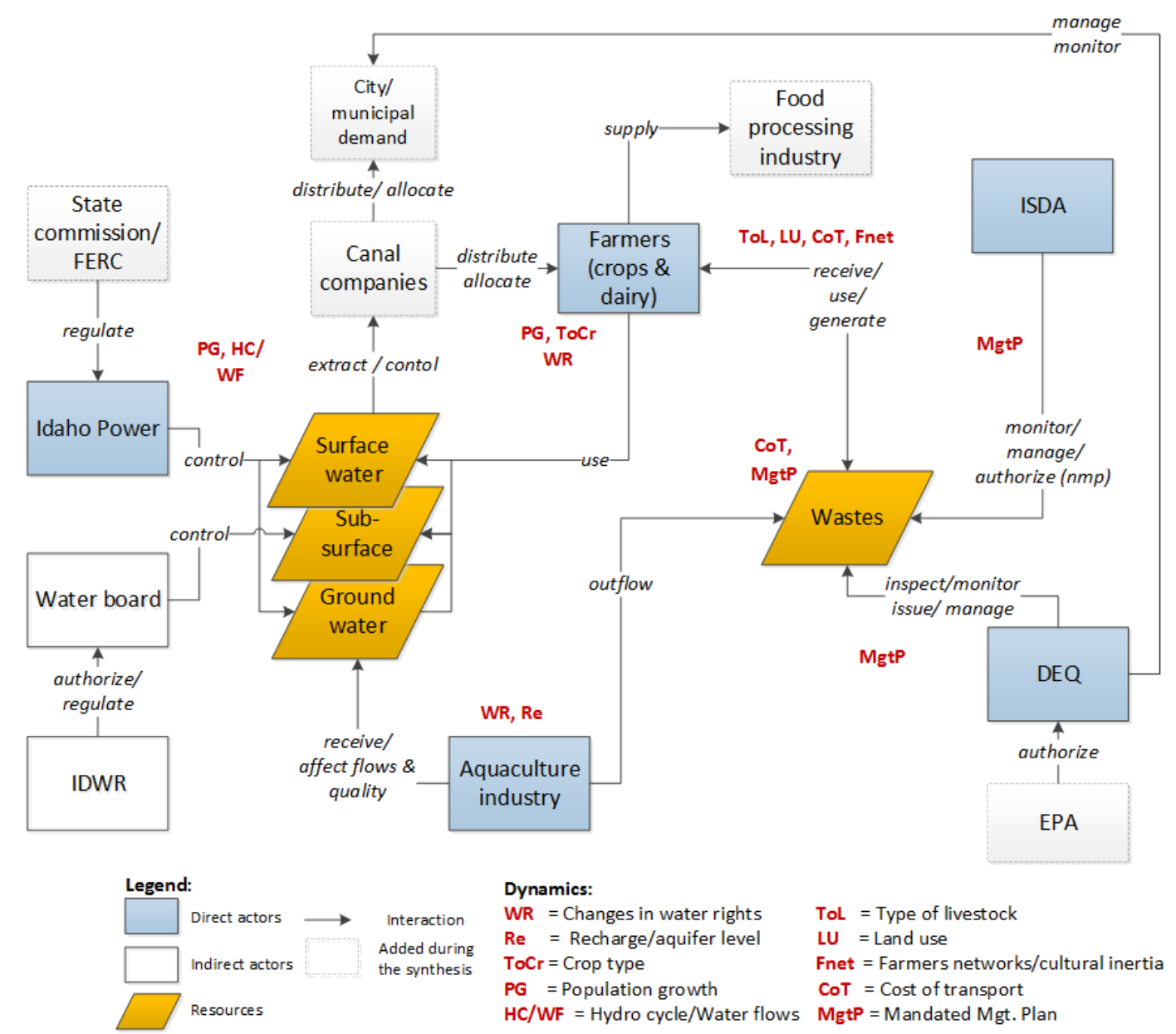

Figure 5: Conceptual model of FEWS in Magic Valley before stakeholder's involvement

Figure 6 presents the conceptual model after local stakeholders' involvement. First, it synthesizes the adjusted understanding of key actors (Figure 2) including the dynamics and processes (Figure 3 and 4) through the interactions. There are several advantages for doing this, for example, if CAFOs and irrigated agriculture are aggregated based on the scientists/modelers group's understanding, the loop between the two actors through biomass wastes utilization is ignored. Second, it maintains the two sub-levels of the water resource (i.e., surface water vs. ground water). Third, it provides a richer understanding of links and feedbacks (italicized actions) as well as potential interventions for dealing with FEWS trade-offs. These links and feedbacks can be further discussed with the stakeholders and can serve as a guide for developing surveys (to parameterize the decisionmaking and behavior strategies of the target agents).

Furthermore, several indirect actors (such as the general public, the state legislature, and canal companies) for water resources were included during the processes of synthesis with stakeholders; whereas for waste and byproducts indirect actors now include the general public, ISDA, and combined DEQ/EPA. This activity further clarified the relationships between indirect actors and key actors including specific interactions (for example, by explicating the difference between an agency that sets regulatory boundaries such as the EPA and an agency that actually enforces regulations at the state level such as the Idaho DEQ). The majority of the dynamics/processes identified by stakeholders are socio-economic in nature, which suggests that we should aim to identify potential solutions and strategies that directly affect the livelihoods of stakeholders. 


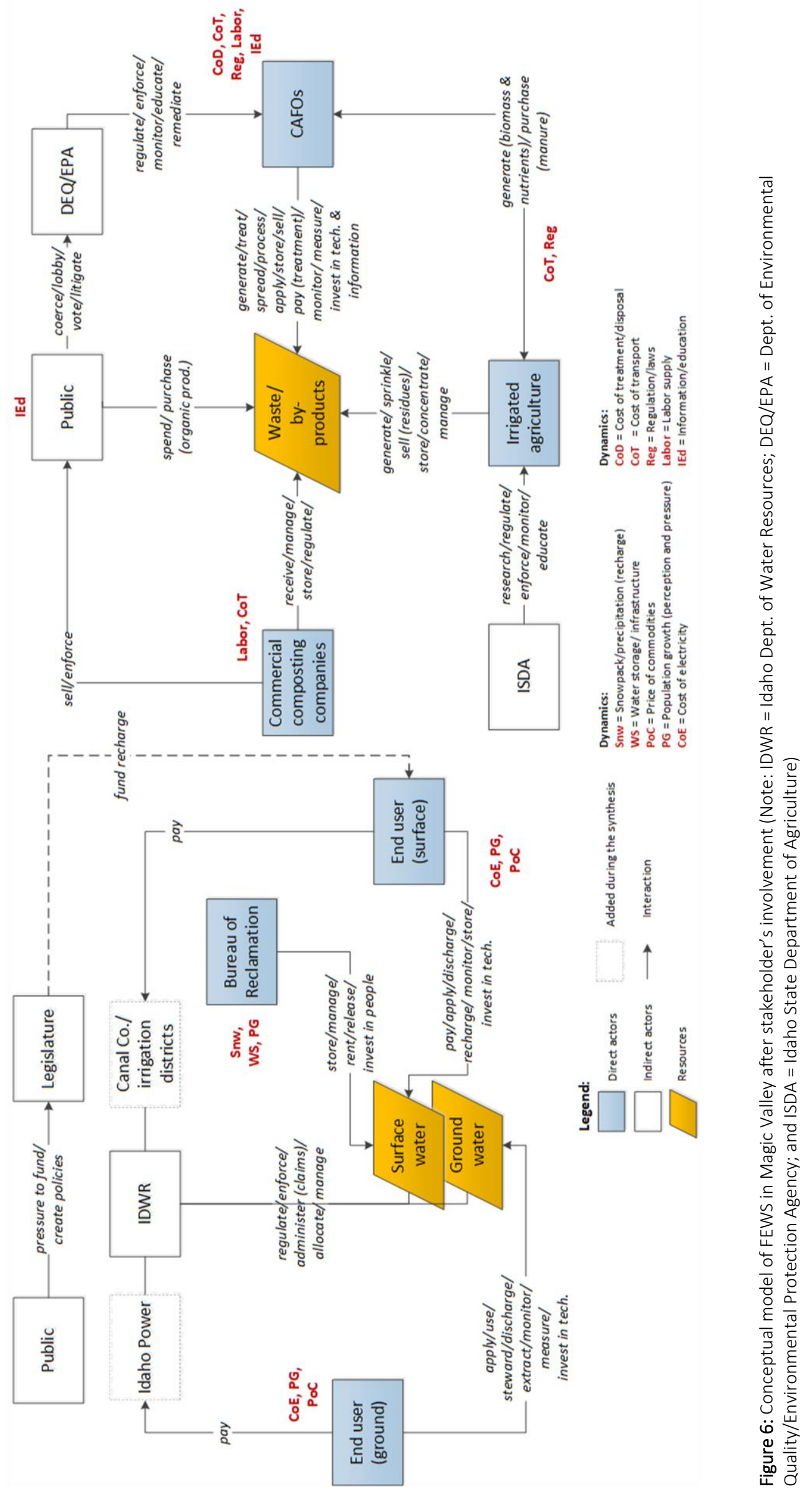


At the end, there are two separate frameworks identified by local stakeholders (Figure 6) to understand the FEWS in the Magic Valley. The main reason for this (according to stakeholders) is that the rules and regulations governing the water and waste systems and (external) actors involved are also divided and separated. These two systems developed somewhat independently in Southern Idaho because of late 19th C. institutional and legal development at both state and federal levels. For the better part of a century (statehood until the 1960s), the primary intervention in the hydrological system was a series of impoundments and improvement designed to provide agricultural water to farmers from the Snake River. In the last fifty years, widespread pumping of groundwater from the Eastern Snake Plain Aquifer has changed this dynamic of using dams and canals to divert surface water to farmers, and now the irrigation and water-return systems are more integrated. Waste flows into surface and groundwater have only become serious concerns in the last few decades, which is why (according to stakeholders) the systems have developed in the way they have.

The conceptual model in Figure 6 may reflect a more realistic, local view of the FEWS in the Magic Valley. The co-construction of the conceptual model with local stakeholders addresses the two uncertainties mentioned above by:

- Utilising local knowledge and observations to identify the structure and elements (including the boundaries/frames) of the target system, as well as the socio-economic and biophysical contexts, which may affect FEWS behaviour, policy measures, and alternative strategies;

- Providing a graphical representation (or visualization) of the target systems and its functions, where the stakeholders can see the various links (or interactions) and feedback loops; and

- Clarifying ambiguous terms and their misinterpretation through stakeholder input.

Moreover, the co-conceptual modelling process builds a shared representation of FEWS. It also helps in establishing trust and confidence with the stakeholders by involving them in the modelling processes. These results support findings by Argent et al. (2016), Beven et al. (2017), Hamilton et al. (2015), Voinov et al. (2016) and Voinov and Bousquet (2010) that involving stakeholders in the modelling process helps to clarify the underlying assumptions, limitations, and capabilities of the resulting models.

To help build the ABM, these dynamics and interventions (i.e., actions) were used as key topics in developing survey questionnaires for key actor groups (e.g., dairy farmers and irrigated agriculture farmers) to parameterize agent decisions and behaviour. It is expected that this method can be compared with the parameterization frameworks of Elsawah et al. (2015) and Smajgl et al. (2011).

\subsection{Lessons learned}

Conceptual models and frameworks are useful platforms for communicating and understanding how the target systems work. It forms the foundation for developing computer code and serves as a basis for model simulation. The primary lessons learned in the process of developing conceptual models of FEWS in a participatory manner, include the capture of the stakeholder knowledge and the structure of the models:

I. Capturing the knowledge of different stakeholders should be done with caution, because not all perceptions of stakeholders are aligned with reality (as well as the science). The subject becomes more complicated if the stakeholders perceive certain parts of the system in value-laden and subjective terms. For example, members of the public in the Magic Valley perceive dairy as the main contributor of water contamination from nutrient leaching in the study area. At the same time, dairy operators maintain that they are subject to tight regulations imposed by the EPA and enforced by the state DEQ on waste management, whereas crop farmers are largely unregulated in terms of fertilizer application. This is related to both subject and linguistic uncertainty and can lead to a model being unintentionally biased: researchers (particularly modelers) must verify the information with stakeholders if it is to be translated to quantifiable and objective data or heuristic rules. By working to reduce this bias and uncertainty, model findings and predictions are better interpreted and communicated to broad audiences (Morgan and Henrion 1990). Combining expert knowledge with local data and Bayesian approaches to account for this uncertainty is proposed by Scholten et al. (2013). In short, neither "expert-only" models nor "stakeholderonly" models of complex systems are likely to be "accurate" representations of real SESs.

II. The structure of models employed to represent "real-world" systems is often a key source of uncertainty. Model structure uncertainty arises from the use of proxy variables, the exclusion of variables (i.e., system 
simplification), and the relationship between natural, human, institutional, and technological variability (Ascough et al., 2008). A specific example from the Magic Valley exercise is in how the perception of drivers of change were different (including the most important drivers) which affects the dynamics of the model. Clarifying differences will reduce uncertainty while it will increase the trust of the involved stakeholders, particularly during the conceptual model design. This can also enhance the stakeholders' sense of ownership and commitment in the succeeding modelling stages. The final output of the modelling exercise can be directly linked to stakeholders' inputs (Pedde et al., 2018). In this way, stakeholders see themselves as an important knowledge source and are more likely be receptive to future research collaborations. After all, the conceptual modelling (including the modelling implementation) is an iterative process to the point that the scientists and stakeholders are satisfied.

III. ARDI is widely applied as a method for developing ABM (Balbi et al., 2010; Dumrongrojwatthana et al., 2011; Gibon et al., 2010; Rouan et al., 2010; Solís et al., 2016). At the same time, it can be useful to identify at an early stage sources of uncertainty with stakeholders (Table 3).

Table 3. ARDI exercise and the level and nature of model context and structure uncertainties*

\begin{tabular}{|c|c|c|}
\hline $\begin{array}{l}\text { ARDI } \\
\text { Conceptual Model } \\
\text { Component }\end{array}$ & $\begin{array}{l}\text { Context uncertainty/ } \\
\text { Content of the model } \\
\text { (Assumptions and choices underlying the } \\
\text { model, which define the boundaries of the } \\
\text { model) }{ }^{B}\end{array}$ & $\begin{array}{c}\text { Model structure } \\
\text { (The relationships between model } \\
\text { components are determined during the co- } \\
\text { construction of the conceptual model) }{ }^{B}\end{array}$ \\
\hline \multirow[t]{2}{*}{$\begin{array}{l}\text { Step 1: Actors and } \\
\text { Resources }\end{array}$} & $\begin{array}{l}\text { The Magic Valley is a food (nutrients)- } \\
\text { energy-water system which supports a wide } \\
\text { range of economic actors such as crop and } \\
\text { livestock producers, food processors, } \\
\text { irrigation and power companies. }\end{array}$ & $\begin{array}{l}\text { Direct actors who will be agents (for the } \\
\text { ABM) such as CAFOs and irrigated } \\
\text { agriculturists that receive and generate the } \\
\text { target resource (e.g., surface and ground } \\
\text { water; and manure/ waste) }\end{array}$ \\
\hline & $\begin{array}{l}\text { Different actors (especially indirect actors) } \\
\text { and resources were identified by } \\
\text { stakeholders and scientists, which reveals } \\
\text { context uncertainty. For example, the } \\
\text { scientists focused on the EPA (a federal rule- } \\
\text { making body), while the stakeholders } \\
\text { focused on the DEQ (a state enforcement } \\
\text { agency). }\end{array}$ & $\begin{array}{l}\text { Waste (if it is not utilized) versus by- } \\
\text { products (if converted to another product) } \\
\text { e.g., from manure to compost }\end{array}$ \\
\hline Step 3: Dynamics & $\begin{array}{l}\text { Scientists tend to pay more attention to the } \\
\text { biophysical/natural side of the processes } \\
\text { whereas the (local) stakeholders are usually } \\
\text { more focused on human-activity based } \\
\text { processes }\end{array}$ & $\begin{array}{l}\text { Sub-models are identified and ranked for } \\
\text { inclusion in the ABM: } \\
\text { 1. Demography (i.e., population); } \\
\text { 2. Economic: (fluctuating input price); } \\
\text { 3. Climate variability (i.e., } \\
\text { precipitation); } \\
\text { 4. Economic: (fluctuating input prices); } \\
\text { and } \\
\text { 5. Policy and regulations (i.e., } \\
\text { implementing of water rights) }\end{array}$ \\
\hline Step 4: Interaction & $\begin{array}{l}\text { Scientists often rely on agriculural or } \\
\text { demographic census data, but those data } \\
\text { may not illustrate flows of resources as } \\
\text { regulated by key actors. These relationships } \\
\text { can be clarified in the modelling exercise } \\
\text { with local stakeholders. }\end{array}$ & $\begin{array}{l}\text { Indirect and direct actors' relationships are } \\
\text { highlighted by local stakeholders. } \\
\text { Clear connections between actors, } \\
\text { resources, and processes through specific } \\
\text { actions (which become rules for an ABM). }\end{array}$ \\
\hline
\end{tabular}

\footnotetext{
* Based on Walker's et al. (2003) level and nature of uncertainty, ambiguity is an epistemic uncertainty and presupposes that more knowledge will reduce ambiguity; qualitative uncertainty functions differently and lies between scenario uncertainty and recognized ignorance. ${ }^{6}$ Warmink et al. (2010).
}

The main challenge in developing a unified conceptual model of a social-ecological system is achieving a balance between these different knowledge systems and their interconnections, which generate uncertainties (Voinov et al., 2016). Thus, it is important to ask the same questions for each stage of the 
ARDI processes and to adjust iteratively the group's understanding of the target system. But it should take into account that there will always be local stakeholders that have vested interests as well as their view on what is right or best to do. Furthermore, a comprehensive analysis of uncertainties in models are rarely achieved (Warmink et al. 2010).

IV. Underscoring differences between knowledge systems and adjusting those knowledge differences to build a shared representation of the FEWS fosters co-learning. This type of collaboration or co-creation of knowledge allows information flows to occur in all directions. Information and knowledge flows from the organizing team, including researchers and modellers, to stakeholders and vice versa (Basco-Carrera et al., 2017; Voinov \& Bousquet, 2010). In the Magic Valley, for example, researchers had focused on aquifer levels as primary drivers of water availability while stakeholders focused on snowpack and impoundment levels; the reality is that surface and aquifer levels are closely connected in the Eastern Snake Plane Aquifer/Upper Snake River Basin region, and that models must take into account both water storage systems to be accurate. Through diagrams, the local stakeholders appreciated water resources (Figure 5) and flows (i.e., hydro-cycle) in a deeper way. They admitted that they tend to only view water as a resource due to the mode of utilization (i.e., ground vs. surface users), strict allocation, and regulations. Also, during the presentation of results, they have identified other actors that may drive change of the FEWS, such as the indigenous communities in the study area. Some of the local stakeholders expressed their enthusiasm in being involved in using the conceptual models to develop systems-level understanding and management tools, even providing data from their own farms and industries.

Furthermore, scientists and modellers tend to use the modelling tools they are most familiar with, but those tools may not fit a system or stakeholder interests in that system. This can lead to attempts to address stakeholders' research priorities using inefficient tools or mischaracterizations of external drivers of change (scenarios), which in turn can make translating results for stakeholders difficult or impossible. For example, scientists involved in the study were suggesting technological and engineering options to address the issue of wastes in the study area. However, during the conceptual modelling exercises (including the follow-up workshops), it was evident that technological solutions such as biodigesters and waste-water resource recovery are not viable options due to economic barriers (Figure 4), which was also supported by the study of Coats and Wilson (2017). Thus, the scientists and the modelling group refocused on the socio-economic and labour aspect of the study area, which were later incorporated in the next modelling stages (i.e., parametrization). At the same time, identified other methods/ techniques to highlight the socio-economic aspect of wastes that do not require modelling techniques (for example, the idea arose during the ARDI process for building a database of "waste" producers and "by-product" consumers in order to create a marketplace).

V. Clarifying interactions between resources and actors allows identification of potential solutions and strategies (including additional key actors) for addressing FEW nexus trade-offs and synergies (Table 3). Information from stakeholders about drivers can also help to understand why certain interventions (e.g., bio-digesters in the Magic Valley) may not be appropriate or implementable in a specific social-ecological context. At the same time, this exercise led to identification of other interventions that do not require modelling but instead suggest other approaches that will readily provide positive impacts for stakeholders (such as a by-products information system for community members). The same challenge had been identified in the establishment and implementation of the wastewater resources recovery facility (WRRF) in the Pacific northwest US. Although WRRFs have been promoted for decades, their adoption has been limited due to a lack of community awareness of, and clear economic benefits for, resource recovery technologies (Coats \& Wilson, 2017).

\section{Conclusions}

In this paper we address the epistemic uncertainty in the development of a FEWS model. Using the ARDI process to build conceptual FEWS models resulted in different outputs from researcher-driven and stakeholder-driven assessments of the Magic Valley FEWS characteristics. While the research team focused on biophysical and mechanistic processes, the stakeholders identified socio-political and economic dynamics as major drivers of decision making and systemic change. By assessing these different knowledge bases and then synthesizing 
perspectives into a single conceptual model we now have a more complete basis for constructing an $A B M$ of the system. At the modelling level, key actors as target agents for the ABM were refined. Stakeholder input at this stage leads to perceptions and processes that are very likely strongly influential on the functioning of the FEWS in the Magic Valley. In this way, uncertainties and errors were evaluated and addressed before these uncertainties can be propagated in modelling and simulation exercises. At the same time, local stakeholders expressed their willingness to be involved in the next stages of the modelling process.

Our study demonstrates some of the benefits of engaging with local stakeholders in the conceptualization of FEWS in the context of SES science and modelling. The modelling exercise in turn can lead to identification of potential solutions which do not necessarily require a modelling technique but which the stakeholders feel would affect positive change in the system. Stakeholders expressed that working through the process with scientists helped to foster a larger-scale, systems-level understanding of the interconnectedness of the food, energy, and water systems. Stakeholders acknowledged that in many cases their decision making and conceptual maps are dominated by the economic needs of their immediate circumstances (i.e., selling milk to food processors, or disposing of industrial waste in the most economical manner possible). Working in a team of diverse stakeholders with different interests and with feedback from the science team helped to deepen the understanding of how individual decision making can affect other parts of the system or system function as a whole. The co-creation of conceptual models incorporating stakeholder knowledge offers a valuable basis for improving FEWS studies.

\section{Acknowledgements}

This research was supported by National Science Foundation (NSF) award SES-1639524 through the Innovations at the Nexus of Food, Energy, and Water Systems program and by an appointment to the Intelligence Community Postdoctoral Research Fellowship Program at the University of Idaho, administered by the Oak Ridge Institute for Science and Education through an interagency agreement between the US Department of Energy (DoE) and the Office of the Director of National Intelligence (ODNI). All findings and conclusions are those of the authors and do not reflect the views of NSF, DoE, or ODNI. The authors would like to express their thanks for the time, effort, and ideas of the project stakeholders during the March 2018 ARDI workshop in Twin Falls, ID.

\section{References}

An, L. (2012). Modeling human decisions in coupled human and natural systems: reviews of agent-based model. Ecological Modelling 229:25-36

Argent, R.M., Sojda, R.S., Giupponi, C., McIntosh, B., Voinov, A.A., \& Maier, H.R. (2016). Best practices for conceptual modelling in environmental planning and management. Environmental Modelling and Software, 80, 113-121. https://doi.org/10.1016/j.envsoft.2016.02.023.

Ascough II, J., Maier, H., Ravalico, J., \& Strudley, M. (2008) Future research challenges for incorporation of uncertainty in environmental and ecological decision-making. Ecological modelling 219, 383-399. https://doi.org/10.1016/j.ecolmodel.2008.07.015.

Balbi, S., Perez, P., \& Giupponi, C. (2010). A spatial agent-based model to explore scenarios of adaptation to climate change in an alpine tourism destination. University Ca'Foscari of Venice, Dept. of Economics Research Paper Series.

Barreteau, O., Abrami, G., Daré, W.S., Du Toit, D., Ferrand, N., Garin, P., Souchère, V., Popova, A., Werey, C. (2012). Collaborative modelling as a boundary institution to handle institutional complexities in water management, Restoring lands-coordinating science, politics and action. Springer, pp. 109-127.

Basco-Carrera, L., Warren, A., van Beek, E., Janoski, A., \& Giardino, A. (2017). Collaborative modelling or participatory modelling? A framework for water resources management. Environmental Modelling and Software, 91, 95-110. https://doi.org/10.1016/j.envsoft.2017.01.014.

Bazilian, M., Rogner, H., Howells, M., Hermann, S., Arent, D., Gielen, D., Steduto, P., Mueller, A., Komor, P., \& Tol, R.S. (2011). Considering the energy, water and food nexus: Towards an integrated modelling approach. Energy Policy, 39(12), 7896-7906. https://doi.org/10.1016/j.enpol.2011.09.039.

Berkes, F., \& Folke, C. (1998). Linking social and ecological systems: management practices and social mechanisms for building resilience. Cambridge University Press, Cambridge, UK.

Beven, K.J., Aspinall, W.P., Bates, P.D., Borgomeo, E., Goda, K., Hall, J.W., Page, T., Phillips, J.C., Smith, P.J., Wagener, T., \& Watson, M. (2017). Epistemic uncertainties and natural hazard risk assessment-part 2: what should constitute good practice? Natural Hazards and Earth System Sciences, 18(10), 2769-2783. https://doi.org/10.5194/nhess-2017-251.

Brugnach, M., Tagg, A., Keil, F., \& de Lange, W.J. (2007) Uncertainty matters: computer models at the science-policy interface. Water Resources Management 21, 1075-1090. https://doi.org/10.1007/s11269-006-9099-y. 
Brugnach, M., Dewulf, A., Pahl-Wostl, C., \& Taillieu, T. (2008). Toward a relational concept of uncertainty: about knowing too little, knowing too differently, and accepting not to know. Ecology and Society 13(2): 30. http://www.ecologyandsociety.org/vol13/iss2/art30/

Clancey, W.J. The knowledge level reinterpreted: modeling how systems interact. Machine Learning 4:285-291.

Coats, E.R., \& Wilson, P.I. (2017). Toward nucleating the concept of the water resource recovery facility (WRRF): perspective from the principal actors. Environmental Science and Technology 51, 4158-4164. doi: 10.1021/acs.est.7b00363.

d'Aquino, P., \& Bah, A. (2013). A participatory modeling process to capture indigenous ways of adaptability to uncertainty: outputs from an experiment in West African drylands. Ecology and Society, 18(4): 16. http://dx.doi.org/10.5751/ES05876-180416.

Daher, B.T., \& Mohtar, R.H. (2015). Water-energy-food (WEF) Nexus Tool 2.0: guiding integrative resource planning and decision-making. Water International 40(5-6), 748-771. https://doi.org/10.1080/02508060.2015.1074148.

Dumrongrojwatthana, P., Le Page, C., Gajaseni, N., \& Trébuil, G. (2011). Co-constructing an agent-based model to mediate land use conflict between herders and foresters in northern Thailand. Journal of Land Use Science 6(2-3), 101-120. https://doi.org/10.1080/1747423X.2011.558596.

Elsawah, S., Guillaume, J.H., Filatova, T., Rook, J., \& Jakeman, A.J. (2015) A methodology for eliciting, representing, and analysing stakeholder knowledge for decision making on complex socio-ecological systems: From cognitive maps to agent-based models. Journal of environmental management 151, 500-516. https://doi.org/10.1016/j.jenvman.2014.11.028.

Endo, A., Tsurita, I., Burnett, K., \& Orencio, P.M. (2017). A review of the current state of research on the water, energy, and food nexus. Journal of Hydrology: Regional Studies, 11(Supplement C), 20-30. https://doi.org/10.1016/j.ejrh.2015.11.010.

Étienne, M. (2013). Companion modelling: a participatory approach to support sustainable development. Springer Science \& Business Media.

Étienne, M., Du Toit, D.R., \& Pollard, S. (2011). ARDI: A Co-construction Method for Participatory Modeling in Natural Resources Management. Ecology \& Society 16(1), 1-14.

Filatova, T., Verburb., P.H., Parker, D.C., \& Stannard, C.A. (2013). Spatial agent-based modles for socio-ecological systems: challenges and prospects. Environmental Modelling and Software 45, 1-7.

Garcia, D.J., \& You, F. (2016). The water-energy-food nexus and process systems engineering: a new focus. Computers \& Chemical Engineering, 91, 49-67. https://doi.org/10.1016/j.compchemeng.2016.03.003.

Gibon, A., Sheeren, D., Monteil, C., Ladet, S., \& Balent, G. (2010). Modelling and simulating change in reforesting mountain landscapes using a social-ecological framework. Landscape Ecology 25, 267-285.

Gourmelon, F., Chlous-Ducharme, F., Kerbiriou, C., Rouan, M., \& Bioret, F. (2013). Role-playing game developed from a modelling process: A relevant participatory tool for sustainable development? A co-construction experiment in an insular biosphere reserve. Land use policy 32, 96-107. https://doi.org/10.1016/j.landusepol.2012.10.015.

Gupta, H.V., Clark, M.P., Vrugt, J.A., Abramowitz, G., \& Ye, M. (2012). Towards a comprehensive assessment of model structural adequacy. Water Resources Research, 48(8), W08301. https://doi.org/10.1029/2011WR011044.

Hamilton, S.H., ElSawah, S., Guillaume, J.H., Jakeman, A.J., \& Pierce, S.A. (2015) Integrated assessment and modelling: overview and synthesis of salient dimensions. Environmental Modelling \& Software 64, 215-229. https://doi.org/10.1016/j.envsoft.2014.12.005.

Klauer, B., \& Brown, J. (2004) Conceptualising imperfect knowledge in public decision-making: ignorance, uncertainty, error and risk situations. Environmental Research, Engineering and Management 1(27), 124-128.

Lynam, T., Mathevet, R., Etienne, M., Stone-Jovicich, S., Leitch, A., Jones, N., Ross, H., Du Toit, D., Pollard, S., Biggs, H., \& Perez, P. (2012) Waypoints on a Journey of Discovery: Mental Models in Human-Environment Interactions. Ecology and Society 17 (3). http://doi.org/10.5751/es-05118-170323

Morgan M.G., \& Henrion M. (1990). Uncertainty: a guide to dealing with uncertainty in quantitative risk and policy analysis. Cambridge University Press, Cambridge, $344 \mathrm{pp}$.

Naivinit, W., Le Page, C, Trebuil, G., \& Gajaseni, N. (2010) Participatory agent-based modelling and simulation of rice production and labor migrations in Northeast Thailand. Environmental Modelling and Software 25, 1345-1358.

NASS (2017). National Agricultural Statistics Service, https://www.agcensus.usda.gov.

Pace D.K. (2003) Thoughts about the simulation conceptual model. In Proceedings of the 2003 Spring Simulation Interoperability Workshop.

Pahl-Wostl, C., M. Craps, A. Dewulf, E. Mostert, D. Tabara, \& Taillieu, T. (2007). Social learning and water resources management. Ecology and Society, 12(2): 5. http://www.ecologyandsociety.org/vol12/iss2/art5/.

Pedde, S., Kok, K., Onigkeit, J., Brown, C., Holman, I., \& Harrison, P.A. (2018). Bridging uncertainty concepts across narratives and simulations in environmental scenarios. Regional Environmental Change 19, 655-666. https://doi.org/10.1007/s10113-018-1338-2.

Refsgaard, J.C., Henriksen, H.J., Harrar, W.G., Scholten, H., \& Kassahun, A. (2005). Quality assurance in model based water management-review of existing practice and outline of new approaches. Environmental Modelling and Software, 20(10), 1201-1215. https://doi.org/10.1016/j.envsoft.2004.07.006.

Refsgaard, J.C., van der Sluijs, J.P., Højberg, A.L., \& Vanrolleghem, P.A. (2007). Uncertainty in the environmental modelling process-a framework and guidance. Environmetal Modelling and Software, 22(11), 1543-1556. https://doi.org/10.1016/j.envsoft.2007.02.004. 
Robinson, S. (2008). Conceptual modelling for simulation part I: definition and requirements. Journal of the Operational Research Society, 59, 278-290.

Rouan, M., Kerbiriou, C., Levrel, H., \& Etienne, M. (2010). A co-modelling process of social and natural dynamics on the isle of Ouessant: Sheep, turf and bikes. Environmental Modelling \& Software 25, 1399-1412.

Scholten, L., Scheidegger, A., Reichert, P., \& Maurer, M. (2013). Combining expert knowledge and local data for improved service life modeling of water supply networks. Environmetal Modelling and Software, 42, 1-16. http://dx.doi.org/10.1016/j.envsoft.2012.11.013.

Smajgl, A., Brown, D.G., Valbuena, D., \& Huigen, M.G.A. (2011). Empirical characterization of agent behaviours in socioecological systems. Environmetal Modelling and Software, 26, 837-844. https://doi.org/10.1016/j.envsoft.2011.02.011.

Solís, P.B., Belmin, C., Leclerc, G., Antona, M., Morataya, R., \& Bommel, P. (2016). Challenges for involving water stakeholders in educational and decision-making participatory processes supported by $\mathrm{ABM}$. International Congress on Environmental Modelling and Software (iEMS), Toulouse, France, July 2016.

Tako, A.A., Kotiadis, K., \& Vasilakis, C. (2010). A conceptual modelling framework for stakeholder participation in simulation studies. Processings of the 2010 Operational Research Society Simulation Conference (SW10), pp. 76-85.

United States Census Bureau, (2017). QuickFacts: Twin Falls City, Idaho. Available at https://www.census.gov/quickfacts/twinfallscityidaho. Accessed November 6, 2018.

Villamor, G.B., \& van Noordwijk, M. (2016) Gender specific land-use decisions and implications for ecosystem services in semi-matrilineal Sumatra. Global Environmental Change 39, 69-80. https://doi.org/10.1016/j.gloenvcha.2016.04.007.

Villamor, G., Palomo, I., Santiago, C., Oteros-Rozas, E., \& Hill, J. (2014). Assessing stakeholders' perceptions and values towards social-ecological systems using participatory methods. Ecological Processes, 3(1), 22. https://doi.org/ 10.1186/s13717-014-0022-9.

Villamor, G.B., Le, Q.B., Djanibekov, U., van Noordwijk, M., \& Vlek, P.L.G. (2014). Biodiversity in rubber agroforests, carbon emissions, and rural livelihoods: An agent-based model of land-use dynamics in lowland Sumatra. Environmetal Modelling and Software, 61, 151-165. https://doi.org/10.1016/j.envsoft.2014.07.013.

Villamor, G.B., Van Noordwijk, M., Troitzsch, K.G., \& Vlek, P.L., (2012) Human Decision Making In Empirical Agent-Based Models: Pitfalls And Caveats For Land-Use Change Policies, ECMS. Citeseer, pp. 631-637.

Voinov, A., \& Bousquet, F. (2010). Modelling with stakeholders. Environmetal Modelling and Software, 25, 1268-1281. https://doi.org/10.1016/j.envsoft.2010.03.007.

Voinov, A., Kolagani, N., McCall, M.K., Glynn, P.D., Kragt, M.E., Ostermann, F.O., Pierce, S.A., \& Ramu, P. (2016). Modelling with stakeholders - next generation. Environmetal Modelling and Software, 77, 196-220. https://doi.org/10.1016/j.envsoft.2015.11.016.

U.S. Department of Agriculture (USDA), National Agricultural Statistics Service. (2012). Census of Agriculture. Available online: https://www.nass.usda.gov/AgCensus/

Walker, W.E., Harremoës, P., Rotmans, J., van der Sluijs, J.P., van Asselt, M.B., Janssen, P., \& Krayer von Krauss, M.P. (2003). Defining uncertainty: a conceptual basis for uncertainty management in model-based decision support. Integrated assessment 4(1), 5-17. https://doi.org/10.1076/iaij.4.1.5.16466.

Warmink, J.J., Janssen, J., Booij, M.J., \& Krol, M.S. (2010) Identification and classification of uncertainties in the application of environmental models. Environmental Modelling \& Software 25, 1518-1527. https://doi.org/10.1016/j.envsoft.2010.04.011

Zhang, X., \& Vesselinov, V.V. (2017). Integrated modeling approach for optimal management of water, energy and food security nexus. Advances in Water Resources, 101, 1-10. https://doi.org/10.1016/j.advwatres.2016.12.017. 